\title{
Movimentos sociais no Brasil contemporâneo: crise econômica e crise política
}

\section{Social movements in contemporary Brazil: economic and political crises}

\author{
Ana Targina Rodrigues Ferraz \\ (D) http://orcid.org/0000-0002-3679-8611
}

Resumo: $\mathrm{O}$ artigo objetiva compreender os movimentos sociais no Brasil a partir da grande crise capitalista iniciada em 2008 e de suas expressões políticas mais visíveis: a organização e mobilização social em redes, fóruns e coletivos. Foram usados dados secundários (artigos científicos e jornalísticos) para mapeamento de aspectos do fenômeno. O mapeamento faz parte de um programa de pesquisa que objetiva compreender as principais tendências das recentes transformações de movimentos sociais e instituições democráticas no Brasil.

Palavras-chave: Manifestações de massa. Movimentos Sociais. Democracia.

\begin{abstract}
This article sets out to understand Social Movements in Brazil in the context of the great capital crisis which began in 2008 and its most visible political expressions: social organisation and social mobilisation (forums, collectives and virtual activism). The article employs secondary data (scientific and journalistic articles) to map of aspects of the phenomena. The mapping forms part of a broad programme of research to understand the main trends (whether retarding or advancing the demands for more democracy) among the most recent transformations of Social Movements and democratic institutions in Brazil.

Keywords: Mass demonstrations. Social Movements. Democracy.
\end{abstract}




\section{Introdução}

N

este artigo, faremos uma reflexão sobre os movimentos sociais no Brasil contemporâneo, da primeira década do século XXI até os dias atuais, momento em que em todo o mundo contestações às consequências da globalização neoliberal (desemprego, empobrecimento, degradação ambiental e conflitos por terra e água) tem início, se espalham territorialmente e cresce o número de participantes dos protestos.

No início deste século, o surgimento de movimentos sociais anti ou alterglobalização, transnacionais e articulados em redes (Gohn, 2013), constituíram a grande novidade.

No Brasil as experiências de gestão participativa (conselhos gestores de políticas públicas e orçamentos participativos) em cidades administradas pelo partido dos trabalhadores (PT), apresentaram-se como modelos de reconhecimento dos movimentos sociais como sujeitos políticos e interlocutores no espaço público. Em toda a América Latina avançava a redemocratização dos Estados nacionais e a luta pela consolidação dos direitos civis, políticos e sociais. $\mathrm{O}$ avanço da constituição de movimentos sociais em torno dos direitos civis (movimento de mulheres, movimento LGBTI, movimento negro, quilombola e indígena) denunciava a invisibilidade social desses indivíduos e a profunda desigualdade, característica da sociedade brasileira e latino-americana. Vivenciamos no período o surgimento do que Gohn (2013) denominou política de identidade. Programas públicos e a criação de conselhos e secretarias voltados para determinados grupos populacionais (mulheres, população negra, população LGBTI, indígenas) no interior das políticas de saúde, educação e assistência social foram desenvolvidos por governos de orientação progressista. $\mathrm{O}$ que provocou o surgimento de um novo tipo de relação entre movimentos sociais e governos e o revigoramento do clientelismo político, em que as perspectivas de ganhos para os grupos redundam em apoio eleitoral e político para partidos e coalizões governantes ${ }^{1}$.

O clientelismo constitui uma característica da cultura política brasileira antes mesmo da instauração da República. Um ensaio de ruptura com esta tradição se esboçou nas décadas de 1970 e 1980 com a constituição de movimentos sociais urbanos e as lutas contra o regime militar, o que 
Entre os anos 1980 e 2000 mudanças importantes processaram-se na configuração dos movimentos sociais. Esses passaram a se caracterizar pela organização em rede, pela horizontalidade e pluralidade ideológica (Gohn, 2014). Tais mudanças talvez possam ser parcialmente explicadas pela necessidade de relações mais democráticas no interior dos próprios movimentos sociais.

Uma leitura da realidade a partir da teoria crítica (marxismo) requer pensar o fenômeno em suas intricadas e necessárias articulações entre economia e política.

Neste trabalho, objetivamos explicar as mais recentes manifestações de rua e as mudanças nas formas de organização, mobilização e comunicação dos movimentos sociais no Brasil como uma das resultantes das mudanças sofridas em nossa economia e no perfil das classes sociais no país. Faremos esta análise situando o país no contexto de aprofundamento da crise estrutural do capitalismo a partir de 2008 e dos doze anos de governos do Partido dos Trabalhadores (PT) no Executivo federal ${ }^{2}$.

\section{Transição democrática, hegemonia neoliberal e movimentos sociais}

Os anos 1970 do século passado tanto marcaram uma mudança profunda no perfil de nossa economia, na direção da industrialização e da constituição de um operariado industrial, quanto na organização dessa classe.

\footnotetext{
levou alguns estudiosos (Scherer-Warren, 1987; Sader, 1988) a tomarem a relação de oposição ao Estado autoritário como uma relação de autonomia na relação com o Estado e que caracterizaria os movimentos sociais construídos no período. $\mathrm{O}$ estreitamento das relações entre movimentos sociais e partidos, movimentos sociais e governos após o fim da ditadura militar marcou o início de um novo tipo de clientelismo político. Nesse modelo, apoios eleitorais passaram a ser trocados por avanços na conquista e consolidação de direitos e na própria construção do movimento (a contratação de militantes de movimentos sociais como assessores parlamentares, especialmente por partidos de esquerda, era considerada uma estratégia importante para que esses militantes pudessem estar mais disponíveis para as tarefas de organização e mobilização dos quadros do movimento e de novos membros), ou seja, o atendimento de necessidades e interesses pessoais de uma ou mais pessoas não era, nesse momento, a sua principal característica.

2 Trabalharemos neste artigo apenas com os mandatos concluídos por Luís Inácio Lula da Silva e Dilma Rousseff.
} 
As ditaduras de Vargas (1930-1945) e militares (1964-1985) foram fundamentais para impulsionar o processo de industrialização periférico e dependente que alterou o perfil da economia e da classe trabalhadora brasileira. O Brasil deixou de ter o café e a exportação de produtos primários como os principais elementos de sua economia. Tornou-se industrial e urbano e passou a contar com uma crescente classe trabalhadora (Sader, 1995).

Durante a ditadura varguista, o controle político dos sindicatos dos trabalhadores foi obtido pela cooptação de lideranças e repressão violenta de seus quadros mais radicais (os militantes do $\mathrm{PCB}^{3}$ foram perseguidos, torturados, mortos ou exilados). Estratégia semelhante foi utilizada pelos militares (Sader, 1995).

O fim do período de expansão da economia nos anos 1970, o desemprego, a deterioração dos salários e das condições de vida nas cidades contribuiu para fomentar o surgimento de organizações operárias de oposição às direções sindicais constituídas durante a ditadura e organizações populares de luta contra a carestia e por serviços de transporte, saúde e educação nas periferias das grandes cidades.

Esse ciclo de lutas operárias e populares que se inicia nos anos 1970 se encerrará nos anos 1990 quando a adesão ao neoliberalismo pelos governos brasileiros afetará profundamente a nossa economia, dando início a um ciclo de desindustrialização e reprimarização ${ }^{4}$ da produção econômica, que conduziu ao aumento do desemprego ${ }^{5}$, ao crescimento da informalidade, do setor de serviços, à precarização ${ }^{6}$ dos vínculos trabalhistas e à degradação

3 O PCB foi criado em 1922 como Partido Comunista do Brasil, vinculado ao PC soviético e se tornou uma importante referência na organização dos trabalhadores brasileiros que, até aquele momento, eram articulados por sindicatos orientados por militantes anarquistas (Sader, 1995).

4 Compreendemos como desindustrialização e reprimarização da produção econômica o declínio relativo e absoluto da produção industrial e o aumento da produção e exportação de soja, gado, ferro e metais (Petras, 2013).

5 Nesse período, a taxa de desemprego, que era de 4,35\% em 1990 chegou a 8,06\% em 2000 (Marques, Rego, 2003).

6 Substituição da estabilidade no emprego por contratos de trabalho temporários ou de duração determinada, contratação de trabalhadores individuais como prestadores de serviços e pessoa jurídica para evitar o pagamento dos encargos trabalhistas e impostos, remuneração nominal 
das condições de trabalho 7 . A adesão brasileira ao neoliberalismo aprofundou as piores características das nossas relações de trabalho e fragilizou o movimento sindical resultando na

[...] queda na quantidade de greves, redução na taxa de sindicalização, proliferação "administrativa" do número de sindicatos - fenômeno possibilitado pela estrutura sindical corporativa de Estado ainda existente no Brasil — fragmentação das negociações e diminuição da quantidade de cláusulas acordadas (Boito Junior; Marcelino, 2010, p. 323).

O movimento operário e popular foi um ator importante na transição brasileira à democracia. A luta pelo direito a ter direitos (Dagnino, 1994) que caracterizou os anos 1970 e 1980, colocou a construção da cidadania no centro das reivindicações dos movimentos sociais que se constituíram no período. Os movimentos sociais que se organizaram nos bairros das cidades de grande e médio porte em defesa da constituição de políticas de moradia, transporte, saúde, educação, emprego, e, no campo, pela distribuição de terras e regularização dos vínculos trabalhistas, além dos movimentos que se organizaram para defender os direitos de mulheres, população negra e população LGBTI, compreendiam a democracia não apenas como modelo, como fórmula para acesso ao poder estatal, mas como condição para que a própria definição de quais são os direitos dos brasileiros pudesse ser feita por esses novos sujeitos políticos (os movimentos sociais) (Dagnino, 1994).

Um partido de caráter classista, o Partido dos Trabalhadores (PT), foi criado em $1980^{\circ}$. A associação entre movimento sindical, movimentos

diferente da remuneração real também para evitar os encargos cuja base para execução é o valor do salário nominal.

7 Aumento das horas trabalhadas, ambientes insalubres, exercício de diferentes tarefas em curto espaço de tempo.

8 O surgimento do Partido dos Trabalhadores em 1980 pode ser compreendido como o resultado de todo o processo de organização da classe trabalhadora no Brasil, tanto nos sindicatos quanto nos movimentos sociais. Segundo os documentos de fundação do partido, esse aglutinaria essas variadas formas de organização da classe e lhe daria direção e sentido, ainda que a disputa pela definição da direção e do sentido fosse intensa no interior do partido, que passou a reunir 
sociais e partido político, observada no período, estabelecia os nexos, no Brasil, do conceito marxista de luta de classes, em que as lutas no âmbito da produção pelas condições de trabalho e pelas condições de reprodução dos trabalhadores no âmbito do Estado (a luta por direitos sociais e por políticas sociais), explicitariam as contradições entre os interesses dos trabalhadores e os interesses dos proprietários do capital. O caráter de classe do Estado, instituição cujo principal objetivo é assegurar as condições necessárias à reprodução da ordem social capitalista, seria desvelado no processo.

O chamado projeto democrático-participativo construído pelo PT estabeleceu um importante horizonte para a luta política do movimento sindical e demais movimentos sociais nos anos 1980 e 1990. O PT rejeitava as experiências socialistas da União Soviética e Europa oriental. Objetivava construir um caminho próprio para o socialismo a partir da inserção das massas trabalhadoras nos processos decisórios nas instâncias do Estado, acirrando o tensionamento entre os interesses do capital e do trabalho na disputa pelos recursos do Estado (Iasi, 2012).

A elaboração da nova Constituição brasileira no final dos anos 1980 foi pautada por esse projeto. A introdução do modelo social-democrata de Estado (o Estado de Bem-Estar Social) na nova carta e as lutas por sua concretização desvelariam os limites desse modelo e a impossibilidade de satisfação das necessidades dos trabalhadores na sociedade capitalista, especialmente na periferia do capitalismo, exasperando os conflitos entre capital e trabalho (Iasi, 2012).

A ascensão do PT ao governo de importantes cidades brasileiras (São Paulo, Porto Alegre e Belo Horizonte) nos anos 1980 e 1990 apresentou o chamado projeto democrático-participativo como viável, ao mesmo tempo em que acirrou as disputas internas ao partido por sua direção e pela direção

muitas correntes de esquerda insatisfeitas com a esquerda brasileira representada pelo PCB (Partido Comunista Brasileiro) e pelo PC do B (Partido Comunista do Brasil) (Sader, 1995) (Iasi, 2012).

9 Contribuiu fortemente para a busca desse caminho próprio o fim das experiências de transição ao socialismo em fins dos anos 1980 e início dos anos 1990 e o desencadeamento de uma crise de rumos para a esquerda em todo o mundo (Sader, 1995). 
do projeto. Correntes dentro do partido passaram a defender as vitórias eleitorais e a gestão do Estado como estratégia para implantar reformas em favor dos interesses dos trabalhadores. A organização dos trabalhadores, o acirramento da luta de classes e a construção do socialismo democrático passaram a ser defendidos por correntes cada vez mais minoritárias no interior do partido (Iasi, 2012).

A associação entre movimentos sociais e o Partido dos Trabalhadores foi importante na definição das características dos movimentos sociais entre os anos 1980 e 1990. A definição de pautas claras, a formalização dos movimentos, a constituição de lideranças, o estabelecimento de regras e de uma hierarquia no processo decisório (coordenações, encontros, congressos), bem como uma determinada leitura da realidade eram o resultado da articulação entre movimentos sociais na sociedade civil e partido político tanto como educador ${ }^{10}$ quanto como participante das instâncias decisórias do Estado (sociedade política/poder executivo e parlamentos).

A valorização da disputa eleitoral, a realização de pequenas reformas e a conquista de avanços na direção da implantação dos direitos civis de parcelas da população brasileira, passaram a também pautar a ação de muitos movimentos sociais brasileiros e suas relações não apenas com o Partido dos Trabalhadores, mas com todos os partidos políticos. E essa foi uma característica importante dos movimentos sociais no país nos anos 1990 em um contexto de forte alinhamento ao ideário neoliberal, contribuindo para inviabilizar a construção do Estado desenhado na Constituição de 1988.

Economicamente, o país tornou-se cada vez mais dependente da exportação de produtos primários, parte de seu parque industrial foi desativado e a força de trabalho industrial desempregada (Petras, 2013). As lutas desencadeadas pelo movimento sindical foram defensivas, para preservação de empregos e salários. As experiências das câmaras setoriais para gestão

10 O Partido dos Trabalhadores desde sua fundação exerceu um importante papel na formação política dos quadros e lideranças de movimentos sociais e do movimento sindical por meio de cursos e cartilhas (Sader, 1995) (Iasi, 1999). 
da crise na indústria automobilística no início dos anos 1990 resultaram em acordos restritos ao setor para assegurar empregos e vendas. Não chegaram a constituir iniciativas próximas aos pactos celebrados entre capital e trabalho na Europa ocidental nos anos 1950.

Para os movimentos sociais, a ascensão do Partido dos Trabalhadores e partidos aliados aos executivos municipais e estaduais significou também a inserção de suas lideranças nos órgãos estatais em cargos e funções de confiança (Braga, 2015) e a ocupação dos espaços institucionais de participação popular (conselhos gestores de políticas públicas e orçamentos participativos). Esse novo cenário exigiu dos movimentos sociais a colocação de seus quadros e de suas principais lideranças à disposição do processo de construção dos arranjos participativos em uma perspectiva propositiva e colaboracionista, substituindo as estratégias de ação direta e confronto, pela negociação e cooperação.

Também o avanço do apelo neoliberal para que a sociedade não esperasse apenas do Estado o atendimento de suas demandas e necessidades ${ }^{11}$ contribuiu para o crescimento de práticas por parte dos movimentos sociais orientadas para a resolução dos problemas da população alvo de suas reivindicações por meio da parceria com ONGs (Organizações Não Governamentais) e governos ou pela sua transformação em ONGs e OSCIPs ${ }^{12}$ (Organizações da Sociedade Civil de Interesse Público).

Observou-se no período um alto nível de institucionalização dos movimentos sociais, tanto no sentido da sua formalização quanto das parcerias com governos e ONGs e inserção nos espaços institucionais. Essa institucionalização representou uma adaptação ao novo contexto, marcado pelo recrudescimento da posição dependente do país na economia mundial.

11 Este apelo se insere no chamado Pluralismo de Bem-Estar, teoria surgida em meio à crise capitalista dos anos 1970, e que coloca em xeque a primazia do Estado na oferta de bens e serviços necessários à promoção do bem-estar dos cidadãos. Segundo essa teoria, o bem-estar dos indivíduos é uma responsabilidade individual e familiar, e, eventualmente essa responsabilidade pode ser compartilhada pela sociedade e pelo Estado (Pereira, 2004).

12 Tais transformações são possíveis pelas Leis ns. 91 de 28 de agosto de 1935 (regulamentadas pelo Decreto n. 50.517, de 2 de maio de 1961), 9.637 de 15 de maio de 1998 e 9.790 de 23 de março de 1999. 
O ciclo de reformas regressivas do Estado brasileiro iniciado com o governo Fernando Collor de Mello (PRN) (1990), aprofunda-se nos governos Fernando Henrique Cardoso (PSDB) de 1994 a 2002. Com a reforma da previdência social dos trabalhadores do setor privado ${ }^{13}$ e os esforços de formação do superávit primário para assegurar o pagamento de parte dos juros de nossas dívidas e alimentar os ganhos de especuladores e detentores de seus títulos, os investimentos sociais do Estado no período foram reduzidos ${ }^{14}$. Além disso, foram feitos esforços deliberados para conter e desmantelar movimento sindical e movimentos sociais tomados como corporativos e apegados à proteção estatal ${ }^{15}$.

Neste contexto, a articulação em redes de movimentos sociais, sindicatos e ONGs conectados em fóruns e coletivos a partir de determinados temas e demandas e por meio de encontros e plenárias, bem como a transnacionalização, parece ter sido a melhor estratégia para enfrentar a nova realidade econômica e política. As redes se caracterizam pela fluidez ${ }^{16}$ na participação de seus membros, pela ausência de hierarquias, pela descentralização e pelo pluralismo organizacional e ideológico (Scherer-Warren, 2008). Nesse

13 A reforma da previdência dos servidores públicos foi realizada pelo governo Lula (PT).

14 Relatórios do TCU sobre a prestação de contas do governo federal nos anos de 1996, 1997 e 1998 demonstram que houve uma redução de 51,86\% dos recursos investidos em saúde e saneamento, 42,48\% na assistência e previdência social e 12,55\% em educação e cultura e um aumento dos recursos destinados ao pagamento dos encargos das dívidas interna e externa (Behring, 2003).

15 Em 1993, o governo Itamar Franco (PMDB) sancionou a Lei n. 8.629, a partir da qual terras "invadidas" por trabalhadores seriam impedidas de se tornarem objeto de desapropriação e reforma agrária, em esforço para combater a principal estratégia de luta (a ocupação de terras) de um dos mais importantes movimentos sociais brasileiros (o MST). Em 1995, greve dos petroleiros foi combatida com tanques do exército que ocuparam as refinarias para desbaratar piquetes e constranger os trabalhadores a voltarem ao trabalho.

16 A fluidez, a partir das reflexões de Scherer-Warren (2008) que trabalha com os conceitos de efemeridade e volatilidade para indicar que nas redes de movimentos sociais as articulações são abertas e plurais em torno de temas comuns (terra, moradia, trabalhos, ecologia, direitos humanos) ou plataformas mais amplas (altermundialização, soberania nacional, projeto de nação, luta contra o neoliberalismo) em que a unidade construída está sujeita a constantes mudanças, se caracteriza pela inexistência de uma definição rígida de quem são os seus participantes, possibilitando que esses se aglutinem a partir do maior ou menor interesse em um tema, problemas, objetivos ou uma plataforma mais ampla. 
sentido, as características das redes de movimentos sociais indicadas por Scherer-Warren têm similaridades com as características dos movimentos que se constroem em redes por meio das novas tecnologias de informação (Castell, 2013) e dos "novíssimos movimentos sociais" (criados a partir das ocupações de praças e ruas na chamada primavera árabe, do movimento dos indignados em Portugal e Espanha e das jornadas de junho de 2013 no Brasil) surgidos depois da grande crise capitalista de 2008 (Gohn, 2017). Essas características, presentes nos movimentos anti ou alterglobalização e no Fórum Social Mundial nos anos 2000, indicam certa insatisfação com a burocratização e a institucionalização de alguns movimentos sociais, especialmente a excessiva proximidade e dependência de partidos políticos e governos.

No Brasil, a ascensão do PT ao Executivo federal após as eleições presidenciais de 2002, contribuiu, nos doze anos em que esteve no poder, para o aprofundamento dessa insatisfação.

\section{Movimentos sociais no Brasil contemporâneo: crise econômica e crise política}

A contribuição das gestões petistas para o aprofundamento de algumas das características apresentadas pelos movimentos sociais brasileiros desde o final dos anos 1990 se processou em dois níveis.

Em primeiro lugar, a gestão da economia não rompeu com a política econômica dos dois governos FHC (PSDB), embora apresente algumas diferenças ${ }^{17}$. A exportação de produtos agrícolas e das atividades mineradoras

17 Segundo Boito Junior, essas diferenças são demarcadas por políticas de recuperação do salário mínimo e de transferência de renda, aumentando a capacidade de consumo das populações de baixa renda, elevação da dotação orçamentária do Banco Nacional de Desenvolvimento Econômico para financiar empresas nacionais com juros baixos, política externa de apoio à empresas brasileiras, medidas para manter a demanda em tempos de crise e ampliação dos investimentos do Estado em infraestrutura (Boito Junior, 2012). 
e a formação do superávit primário continuaram a ser fundamentais na política econômica.

Os aumentos reais do salário mínimo, a ampliação do acesso ao crédito e o investimento em obras de infraestrutura (hidrelétricas e estradas) estimularam a atividade econômica e foram importantes para a incorporação de parte dos trabalhadores brasileiros ao mercado formal de trabalho (Pochmann, 2012). Essas iniciativas, tomadas para o enfrentamento da crise capitalista de 2008, proporcionaram em 2010 um maior crescimento do PIB em relação aos governos FHC (Fagnani, 2011). Entretanto, apesar dos aumentos reais dos salários de algumas categorias de trabalhadores, a massa salarial dos trabalhadores brasileiros continuou baixa e a maioria dos empregos formais gerados se situava no setor de serviços, onde imperam a terceirização, ocupações pouco especializadas, mal remuneradas e péssimas condições de trabalho (Pochmann, 2012) 18. $^{18}$.

Algumas medidas de ampliação do acesso aos serviços públicos de educação e saúde significaram o aumento do financiamento público de serviços privados.

$\mathrm{Na}$ educação, o governo federal ampliou o número de vagas no ensino superior e nas escolas de educação tecnológica para o ensino médio, mas essa ampliação se fez por meio, principalmente, do financiamento público da rede privada de educação superior. Na saúde, as organizações sociais se tornaram gestoras de hospitais públicos por meio de convênios e contratos ${ }^{19}$.

18 Segundo Marcio Pochmann, 94\% das vagas abertas até 2010 remuneravam o trabalhador em até 1,5 salário mínimo e mais de $50 \%$ dessas vagas deslocaram-se do setor industrial para o setor de serviços entre as décadas de 1990 e 2000.

19 O PROUNI (programa de financiamento de estudantes pobres em faculdades privadas por meio de isenções fiscais) e a ampliação do FIES (programa de crédito educativo para o pagamento de faculdades privadas) foram os principais programas adotados. Em 2010, foi criada a Empresa Brasileira de Serviços Hospitalares (EBSERH, uma empresa pública de direito privado) para gestão dos hospitais universitários (hospitais federais), aprofundando o processo de privatização e mercantilização das principais políticas sociais brasileiras. O que significa a introdução e consolidação da lógica da acumulação e busca de superlucros como principal objetivo na oferta dos serviços de educação e saúde. A prestação de serviços de qualidade e o atendimento das necessidades dos usuários são secundários em face da perseguição de lucros cada vez maiores, resultando em salas de aula lotadas, professores mal remunerados, aligeiramento na formação com cursos universitários de curta duração; atendimentos em saúde cada vez mais ligeiros, 
Mesmo a criação, depois de décadas de luta do movimento nacional de moradia, de um programa federal de habitação, esse programa (o programa Minha Casa, Minha Vida) foi formulado a partir de conversas com empresários do setor imobiliário e da construção civil e sua principal característica é o financiamento público de empreendimentos imobiliários privados, por meio de acesso ao crédito habitacional nos bancos públicos (Parmezani, 2013).

Durante as gestões petistas no executivo federal o desemprego diminuiu, o acesso ao crédito para o consumo aumentou e o programa Bolsa Família tirou milhões de famílias brasileiras da pobreza absoluta (Fagnani, 2011). Entretanto, a massa de empregos criada caracteriza-se pela baixa remuneração e precariedade e não houve uma melhoria substantiva nas condições de vida dos milhões de trabalhadores brasileiros que dependem de transporte público e dos serviços públicos de educação e saúde. Os investimentos federais nessas políticas simplesmente não cresceram ou tiveram um crescimento residual nesse período (Pochmann, 2012). Ou seja, as condições de vida dos brasileiros em nossas cidades continuaram muito ruins.

Não houve uma alteração significativa na estrutura de rendimentos entre as classes sociais brasileiras. $O$ suposto crescimento das chamadas classes médias foi assentado em parâmetros extremamente baixos de rendimento e consumo ${ }^{20}$ e os trabalhadores continuaram a ser os grandes financiadores do Estado brasileiro ${ }^{21}$. 0 intenso escrutínio ${ }^{22}$ realizado pelos

médicos e enfermeiros também mal remunerados, excesso de exames para aumentar os gastos dos usuários, patologização e medicalização crescente de todas as dimensões da vida, também de forma a aumentar a recorrência aos serviços privados de saúde.

20 Segundo a Secretaria de Assuntos Estratégicos da Presidência da República, encontram-se na classe média todos os brasileiros que recebem uma renda mensal per capita entre 291,00 e 1.019,00 (Brasil, SAE apud Braga, 2015).

21 Diversos estudos revelam que a carga tributária brasileira aumentou muito nos últimos anos, saltou de 29\% para 35\% do PIB no período de 1994 à 2006 (SRFB, 2007). De fato, já é mais alta que a de muitos países centrais. Mas o Brasil, ao contrário dos países desenvolvidos, tira a maior parte de sua receita de tributos indiretos e cumulativos, que oneram mais o trabalhador e os mais pobres, pois tem uma alta carga tributária sobre o consumo - mais da metade da carga provém de tributos que incidem sobre bens e serviços - e uma baixa tributação sobre a renda $-28 \%$ da arrecadação tributária. (Salvador, 2010, p. 208-209)

22 Esquemas de corrupção descobertos nos governos Sarney (1985-1989) e FHC (1995-1998; 1999-2002) não foram investigados com a mesma celeridade e amplitude. 
agentes da polícia federal e pelos órgãos de controle do Executivo de nossas arraigadas práticas de corrupção dos agentes públicos durante as gestões petistas colaborou para a construção de um quadro de crescente insatisfação entre os brasileiros.

Nos últimos anos houve um aumento significativo no número de greves de trabalhadores realizadas no país (Boito Junior; Marcelino, 2010), (Boito Junior, 2014). Cresceram também o ativismo virtual e os coletivos de jovens organizados de maneira horizontal, descentralizada e em defesa dos direitos da população negra, das mulheres e da população LGBTI. Também cresceram os coletivos de artistas das mais diversas áreas (artes plásticas, cinema, teatro, música, dança, artesanato) cuja principal característica tem sido o uso das novas tecnologias de informação e das mídias sociais (facebook, twitter, instagram, whatsapp) como formas de comunicação, articulação e divulgação das ideias e bandeiras dos movimentos (Scherer-Warren, 2008, 2014).

A situação econômica e social em particular da parcela jovem da população brasileira não se alterou significativamente. Embora essa parcela da população tenha hoje maior escolarização, ela tem trabalhado mais horas, em atividades que não correspondem a sua escolarização, e tem sido mal remunerada ${ }^{23}$. E não há no horizonte perspectivas de alteração desse quadro. $O$ país continua a depender de investimentos externos de risco para equilibrar suas contas e qualquer projeto de desenvolvimento econômico e social autônomo, baseado no mercado interno e nas trocas comerciais com países que escapem ao eixo Europa e Estados Unidos, tem sido objeto de duras críticas.

Ou seja, o quadro de deterioração da economia e das condições de vida e trabalho dos brasileiros criou um ambiente para a organização e a mobilização de parcelas significativas da população, ainda que sem uma direção ou projeto político bem definido.

Em segundo lugar, em sentido político restrito, as gestões petistas no governo federal estimularam uma situação de silêncio e colaboração entre

23 Das vagas formais criadas cuja remuneração não é superior a 1,5 salário mínimo, 60\% foram ocupadas por jovens entre 18 e 28 anos (Pochmann, 2012). 
governo, movimento sindical e movimentos sociais. $\mathrm{O}$ apoio aos governos petistas, a desmobilização para proteger o governo contra a ofensiva das oposições, conservadoras ou não, caracterizaram os dois mandatos de Luís Inácio Lula da Silva e o primeiro mandato de Dilma Rousseff. Contribuiu para tanto a combinação de duas estratégias: primeiro a incorporação de militantes petistas e de movimentos sociais a milhares de cargos administrativos de função comissionada no Executivo e nas empresas estatais e o controle sindical dos fundos de pensão; segundo o atendimento de algumas necessidades dos setores mais empobrecidos da população brasileira por meio do programa Bolsa Família, da ampliação do acesso ao crédito e dos aumentos reais do salário mínimo (Braga, 2015).

Os ganhos sociais conquistados no período também foram importantes para a sustentação social das duas gestões e para a vitória eleitoral do partido em 2010 e em 2014 com Dilma Rousseff.

Contudo, uma inédita exposição pública das alianças do PT com partidos políticos dos mais diferentes perfis ideológicos e da perpetuação de uma relação entre Executivo, Legislativo e empresariado apoiada exclusivamente na prática da compra de apoios eleitorais por meio do uso de recursos do Estado para o financiamento de obras, compras dos insumos necessários ao funcionamento da máquina estatal e acordos econômicos vantajosos para empresas brasileiras, revelaram o aprofundamento de um projeto de poder que nada mais guardava do projeto democrático-participativo, transformado em mera estratégia de gestão do Estado. Embora em todas as gestões petistas no governo federal tenha crescido o número de áreas em que foram realizadas conferências nacionais para discussão da política, assim como as consultas públicas para projetos governamentais (Fagnani, 2011), todas as decisões tomadas pelo governo federal estavam subordinadas ao projeto político de sustentação do modelo econômico de desenvolvimento baseado na subordinação aos interesses do capital financeiro internacional e na produção de produtos primários (Petras, 2013). Houve um aprofundamento de relações com os movimentos sociais nas quais esses se transformaram em meros apoiadores das decisões partidárias e programas governamentais, esvaziando as possibilidades de uma relação baseada na crítica e na retroalimentação entre partido e movimentos. 
A execução de um modelo de desenvolvimento (Castelo, 2012) (Petras, 2013) que não alterou a posição subordinada do país na economia mundial, aumentou o número de trabalhadores em relações de trabalho precárias e não reduziu de forma substantiva nossas desigualdades sociais. A relação com os movimentos sociais foi desde o início formal e não substantiva ${ }^{24} \mathrm{e}$ criou as condições para uma reconfiguração dos movimentos sociais marcada pela indignação com a situação econômica e pelo anseio de ruptura com as chamadas "velhas" formas de organização e de fazer política do movimento sindical e dos mais tradicionais movimentos sociais. $\mathrm{O}$ crescimento da organização em redes, fóruns, frentes e coletivos para articulação de demandas e construção de uma nova sociabilidade pautada pela autonomia e horizontalidade como princípios (Gohn, 2018), buscou romper com práticas políticas mais tradicionais caracterizadas pela negociação, conciliação e acordos entre lideranças de movimentos sociais, governos e partidos. Uma vez no poder, o PT não rompeu com tais práticas e contribuiu para que fossem postas em xeque e crescesse o anseio por mudanças ou mesmo rupturas nas relações entre partidos, governos e movimentos sociais, pautadas pela conciliação.

\section{Conclusão}

Embora algumas das atuais características dos movimentos sociais estivessem presentes desde o final dos anos 1990 e início dos anos 2000, as novas mídias sociais e tecnologias de informação e comunicação parecem ter proporcionado uma maior visibilidade a um número também crescente de inquietações e demandas e aumentado sua capacidade de articulação,

24 A criação do conselho nacional de desenvolvimento econômico e social no início do primeiro governo Lula (2003) parecia sinalizar para uma participação mais substantiva dos movimentos sociais nas decisões do Executivo federal. Entretanto, o conselho tinha caráter consultivo e foi composto majoritariamente por organizações representativas dos interesses empresariais, dos donos de terra e dos detentores do capital financeiro. As organizações representativas das classes trabalhadoras eram consideradas "parceiras", coadjuvantes nas discussões realizadas no conselho. 
pela rapidez e facilidade com que ideias e propostas circulam não apenas entre os diretamente interessados na questão, mas também entre os seus próximos em progressão geométrica (Loveluck, 2018). O que se por um lado aumenta a capilaridade de movimentos que agora se organizam como redes, fóruns, frentes e coletivos, por outro, os tornam cada vez mais plurais em suas formas de organização e em seus horizontes ideológicos e políticos e dificulta a construção de projetos societários de oposição e enfrentamento à ordem do capital. Na construção dos atuais movimentos sociais parece sobressair a necessidade de constituição, no mundo virtual e no mundo real, de espaços e formas de sociabilidade em que diferentes ideias, posições e mesmo projetos societários possam ser expressos. O mais importante parece ser a própria existência do movimento e as formas de expressão de seus anseios (a música, o teatro, o escracho, o filme, o meme). Uma vez que pouco se espera das estruturas políticas existentes (partidos, sindicatos, parlamentos), a maior conquista, no momento, parece ser o desejo, ainda que sem direção, de mudar. Quais mudanças e como essas mudanças serão processadas é uma questão em aberto.

\section{Referências}

BOITO JUNIOR, Armando; MARCELINO, Paula. O sindicalismo deixou a crise para trás? um novo ciclo de greves na década de 2000. Caderno CRH, Salvador, v. 23, n. 59, p. 323338, Maio/Ago. 2010.

. As bases políticas do neodesenvolvimentismo. In: Fórum Econômico da Fundação Getúlio Vargas, 2012, São Paulo.

Sindicalismo e movimento popular. Caros Amigos, São Paulo, ano XVII, n. 205, p. 19-21, abril de 2014. Entrevista concedida a Gilberto Maringone.

BRAGA, Ruy. A pulsão plebeia: trabalho, precariedade e rebeliões sociais. São Paulo: Alameda, 2015.

CASTELLS, Manuel. Redes de indignação e esperança: movimentos sociais na era da internet. 1. ed. Rio de Janeiro: Zahar, 2013.

CASTELO, Rodrigo. O novo desenvolvimentismo e a decadência ideológica do pensamento econômico brasileiro. In: Revista Serviço Social e Sociedade, São Paulo, n. 112, p. 613636, out./dez. 2012. 
DAGNINO, Evelina. Os movimentos sociais e a emergência de uma nova noção de cidadania. In: DAGNINO, Evelina (Org.). Os anos 90: política e sociedade no Brasil. São Paulo: Brasiliense, 1994, p. 103-115.

FAGNANI, Eduardo. A política social do governo Lula (2003-2010): perspectiva histórica. In: Revista Ser Social, Brasília, v. 13, n. 28, p. 41-80, jan./jun. 2011.

GOHN, Maria da Glória. Movimentos sociais e redes de mobilizações sociais civis no Brasil contemporâneo. 7. ed. Petropólis, RJ: Vozes, 2013.

2014.

BRINGEL, M. Breno. Movimentos sociais na era global. 2. ed. Petropólis, RJ: Vozes,

Manifestações e protestos no Brasil: correntes e contracorrentes na atualidade. São Paulo: Cortez, 2017. (Coleção questões da nossa época; v. 59).

Jovens na política na atualidade: uma nova cultura de participação. In: Caderno CRH, Salvador, v. 31, n. 82, p. 117-133, jan.-abr. 2018.

IASI, Mauro Luis. Processo de Consciência. São Paulo: Centro de Documentação e Pesquisa Vergueiro, 1999.

Democracia de cooptação e o apassivamento da classe trabalhadora. In: Salvador, Evilásio [et al.] (Orgs.). Financeirização, fundo público e política social. São Paulo: Cortez, 2012, p. 285-317.

LOVELUCK, Benjamin. Redes, liberdades e controle: uma genealogia política da internet. Petropólis, Rio de Janeiro: Vozes, 2018.

MARQUES, Rosa Maria; REGO, J. M. (Orgs.). Economia brasileira. 3. ed. São Paulo: Saraiva, 2010.

PARMEZANI, Eliane. Especulação explode nas periferias: a expansão desordenada do mercado imobiliário avança nas regiões mais afastadas dos centros metropolitanos e acelera a deterioração da vida nas cidades. Caros Amigos, São Paulo, ano XVI, n. 190, p. 10-13, 2013.

PEREIRA, Potyara Amazoneida Pereira. Pluralismo de bem-estar ou configuração plural da política social sob o neoliberalismo. In: BOSCHETTI, Ivanete et al. (Orgs.). Política social: alternativas ao neoliberalismo. Brasília: UnB, 2004, p. 135-159.

PETRAS, James. Brasil: capitalismo extrativo e o grande retrocesso. In: Revista Praia Vermelha, Rio de Janeiro, v. 23, n. 1, jan./jun. 2013, p. 69-116.

POCHMANN, Marcio. Nova classe média? O trabalho na base da pirâmide salarial brasileira. São Paulo: Boitempo, 2012.

SCHERER-WARREN, Ilse. O caráter dos novos movimentos sociais. In: SCHERER-WARREN, Ilse; KRISCHKE, Paulo J. (Orgs.). Uma revolução no cotidiano? Os novos movimentos sociais na América do Sul. São Paulo: Brasiliense, 1987, p. 35-53.

Redes de movimentos sociais na América Latina. In: Caderno CRH, Salvador, v. 21, n. 54, p. 505-517, set./dez., 2008. 
SCHERER-WARREN, Ilse. Manifestações de rua no Brasil 2013: encontros e desencontros na política. Caderno CRH, Salvador, v. 27, n. 71, p. 417-429, maio/ago. 2014.

SADER, Eder. Quando novos personagens entraram em cena: experiências, falas e lutas dos trabalhadores da Grande São Paulo, 1970-80. Rio de Janeiro: Paz e Terra, 1988.

SADER, Emir. $O$ anjo torto: esquerda (e direita) no Brasil. São Paulo: Brasiliense, 1995.

SALVADOR, Evilásio. Fundo público e seguridade social no Brasil. São Paulo: Cortez, 2010.

\section{Sobre a autora}

Ana Targina Rodrigues Ferraz - Doutora em Ciências Sociais. Professora associada do Departamento de Serviço Social.

E-mail: anatargina@uol.com.br 